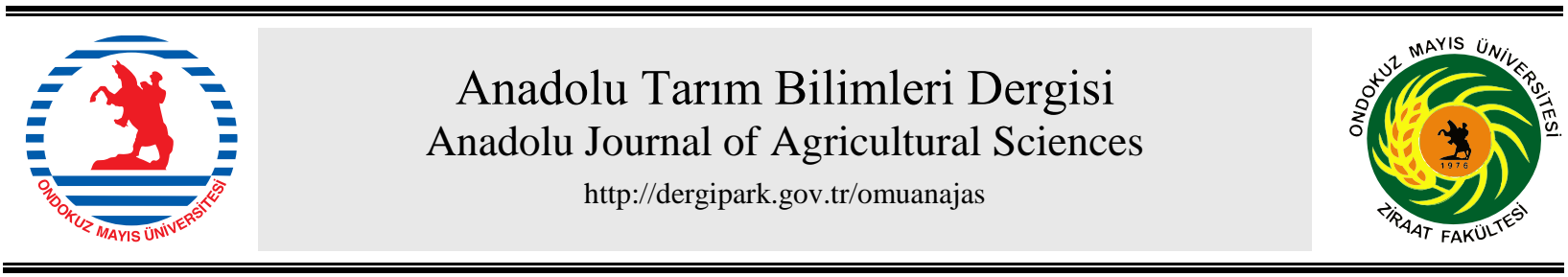

\section{Araştırma/Research}

Anadolu Tarım Bilim. Derg./Anadolu J Agr Sci, 35 (2020) ISSN: 1308-8750 (Print) 1308-8769 (Online) doi: 10.7161/omuanajas.688267

\title{
Tuzlu toprakların hidrokimyasal parametrelerinin laboratuvar koşullarında belirlenmesi
}

\author{
Seyit Ali Dursun ${ }^{\mathrm{a}^{*}}$, 다 Fariz Mikailsoy ${ }^{\mathrm{b}}$ \\ ${ }^{a}$ Aksaray Üniversitesi, Teknik Bilimler MYO, Bitkisel ve Hayvansal Üretim Bölümü, Aksaray, Türkiye \\ ${ }^{b}$ Iğdır Üniversitesi, Ziraat Fakültesi, Toprak Bilimi ve Bitki Besleme Bölümü, Iğdır, Türkiye
}

*Sorumlu yazar/corresponding author: saddursun@aksaray.edu.tr

Geliş/Received 12/02/2020 Kabul/Accepted 30/04/2020

\begin{abstract}
ÖZET
Bu çalışma, yıllık yağışın az, aşırı buharlaşmanın ve taban suyunun yüzeye yakın olması nedeniyle oluşan tuzluluğun, bitkinin gelişmesine, verime ve toprağın çoraklaşmasına olumsuz etkisinin yıkamayla ortadan kaldırılması amacıyla yapılmıştır. Tuzlu toprakların ıslahı, maliyetli ve zaman gerektiren bir süreçtir. Çözünebilir tuzların yıkanması amacıyla kullanılan matematiksel yöntemler, toprakların 1slahında su-tuz rejiminin modellenmesinde doğrudan ve ters problemlerin çözümü için yaygın olarak kullanılmaktadır. Tuz taşınım modelinin uygulanabilirliği, modelin süreçlerini tanımlayan hidrodinamiklerin diferansiyel eşitliklerinin deneysel parametrelerinin doğruluğuna bağlıdır. Laboratuvar koşullarında yapılan çalışmada $20 \mathrm{~cm}$ çapında kolonlar kullanılarak toprakta tuz taşınımının hidrokimyasal göstericileri olan; konvektif difüzyon ve dispersiyon (yayılma) parametreleri, toprak gözeneklerindeki su akış hızı belirlenmiștir. Y1kama döneminde $\mathrm{CI}^{-}$ve $\mathrm{SO}_{4}{ }^{=}$iyonları için hidrokimyasal dispersiyon parametresi $(\lambda)$, değerleri sırasıyla $9.26 \cdot 10^{-2} \mathrm{~m}$ ve $9.60 \cdot 10^{-2} \mathrm{~m}$; konvektif difüzyon parametresi (D) ise $4.51 \cdot 10^{-3} \mathrm{~m}^{2}$ gün $^{-1}$ ve $4.67 \cdot 10^{-3} \mathrm{~m}^{2}$ gün-1 olarak belirlenmiştir.
\end{abstract}

\section{Determination of hydrochemical parameters in laboratory conditions of saline soils}

\section{ABSTRACT}

This study, less annual rainfall, saltiness due to excessive evaporation and groundwater being close to the surface, negative effects on plant growth, the yield and aridification of soil was carried out to eliminate the leaching. Reclamation of saline soils is a costly and time-consuming process. Mathematical methods used for leaching soluble salts are widely used for the solution of direct and inverse problems in the modelling of the water-salt regime in the reclamation of soils. The applicability of the salt transport model depends on the accuracy of the experimental parameters of the differential equations of hydrodynamics that define the processes of the model. In the study carried out under laboratory conditions, hydrochemical indicators of salt transport in soil using $20 \mathrm{~cm}$ diameter columns; convective diffusion and dispersion (diffusion) parameters, water flow rate in soil pores were determined. During the leaching period, the hydrochemical dispersion parameter $(\lambda)$, for $\mathrm{CI}^{-}$and $\mathrm{SO}_{4}{ }^{=}$ions values $9.26 \cdot 10^{-2} \mathrm{~m}$ and $9.60 \cdot 10^{-2} \mathrm{~m}$; the convective diffusion parameter (D) were determined as $4.51 \cdot 10^{-3} \mathrm{~m}^{2}$ day $^{-1}$ and $4.67 \cdot 10^{-3} \mathrm{~m}^{2}$ day $^{-1}$, respectively.
Anahtar Sözcükler:

Hidrodinamik parametre Tuzlu toprak Y1kama suyu normu Y1kama
Keywords: Hydrodynamic parameter Leaching water norm Leaching Saline soils 


\section{Giriş}

Tarımsal üretimin sürdürülebilir olması, üretimin ana kaynağı olan toprağın korunmasına ve suyun rasyonel kullanılmasına bağlıdır. Özellikle yıllık yağışın az, buharlaşmanın yüksek ve taban suyunun yüzeye yakın olduğu durumlarda toprakta tuzluluk meydana gelmektedir. $\mathrm{Bu}$ durum tarımsal üretim dengesinin bozulmasına, toprağın çoraklaşmasına, verimliliğin ve sürdürülebilir tarım alanlarının azalmasına neden olmaktadır. Dünya genelinde 12.781 milyon hektar tarım arazisi tuzdan etkilenmiş ve üretimde sınırlanmalar meydana geldiği bildirilmektedir. Ülkemiz topraklarında ise yüzölçümün \%2'sini çorak araziler oluşturmaktadır (FAO, 2008; Sönmez, 2011).

Yıkama, tuzlu toprakların 1slahında en önemli yöntemlerden biridir. Tuzlu toprakların yıkanmasında önemli hacimde tatlı su kullanılmaktadır. Dünya'da tatlı su kaynaklarının giderek azalması nedeniyle, toprak 1slahında kullanılan yıkama suyu miktarının ve uygulama süresinin belirlenmesi, tuzlu toprakların ıslahının önemli aşamalarından biridir. Yıkama suyu miktarının ve uygulama süresinin belirlenmesinde karşılaşılan sorunların giderilmesinde farklı yöntemler uygulanmaktadır. $\mathrm{Bu}$ yöntemlerden biri olan matematiksel metotlar, günümüzde bu sorunların çözülmesinde yaygın bir şekilde kullanılmaktadır. Toprakta tuz taşınım denkleminin çözümünün yıkama suyu miktarının ve uygulama süresinin hesaplanmasında kullanılmasının güvenirliği, hidrokimyasal parametrelerin deneysel olarak belirlenmesinin doğruluğuna önemli düzeyde bağlı olmaktadır. Araştırmacılar (Mikaylov, 1981; 2007; Vaksman ve ark., 1981; Aydarov,1985; Mikayilov ve Azizov, 1985; Verigin ve ark., 1986; Aydarov ve ark., 1988; Ekberli ve ark., 2001; Shein ve ark., 2001; Dursun, 2017;) tarafından yıkama suyu miktarının ve uygulama süresinin belirlenmesi için tuz taşınım modelinin uygulanmasına ait yapılan çalışmalarda, hidrokimyasal parametrelerin detaylı olarak değerlendirilmesinin çok önemli olduğu vurgulanmıştır.

$\mathrm{Bu}$ çalışmada, tuzlu toprakların yıkanmasında tuz taşınım modeli esas alınarak, laboratuvar koşullarında metal kolonlar kullanılarak hidrokimyasal parametrelerin deneysel olarak belirlenmesi ve elde edilen sonuçların sslah edilecek tuzlu topraklarin yıkanmasinda kullanılmasiyla zaman, maliyet ve su tasarrufu sağlanması amaçlanmıştır.

\subsection{Toprakta çözünmüs tuzların hareketinin matematiksel ifadesi}

Toprak gözeneklerinde çözünmüş tuzların yıkama suyu ile islahının incelenmesi amacıyla kullanılan (Verigin, 1953; Pachepsky, 1990; Shein, 2005; Mikayilov, 2007) kısmi türevli diferansiyel denklem aşağıdaki biçimde yazılabilir.

$$
\begin{aligned}
& \frac{\partial}{\partial t}\left(\theta C+\rho b_{1}+b_{2}\right) \\
& =\theta D \frac{\partial^{2} C}{\partial x^{2}}-\theta v \frac{\partial C}{\partial x}-\theta \mu C, \\
& b_{1}=k C, \quad \frac{\partial b_{2}}{\partial t}=-\gamma\left(C_{s}-C\right)
\end{aligned}
$$

Burada; $\mathrm{C}(\mathrm{x}, \mathrm{t})$ - toprağın $\mathrm{x}$ derinliğinde $\mathrm{t}$ zamanda çözülmüş tuzların konsantrasyonu $\left(\mathrm{me} \mathrm{L}^{-1}\right) ; \mathrm{b}_{1}(\mathrm{x}, \mathrm{t})-$ toprağın $\mathrm{x}$ derinliğinde $\mathrm{t}$ zamanda emilmiş tuzların konsantrasyonu (me L $\left.{ }^{-1}\right) ; b_{2}(x, t)$ - toprağın $\mathrm{x}$ derinliğinde $\mathrm{t}$ zamanda kristallerde veya katı fazdaki tuzların konsantrasyonu (me $\mathrm{L}^{-1}$ ); $\mathrm{C}_{\mathrm{s}}$-toprak çözeltisindeki çözünebilir tuzun maksimum konsantarsyonu $\left(\mathrm{me} \mathrm{L}^{-1}\right)$; $\rho$-toprak hacim ağırlı̆ğ $\left(\mathrm{g} \mathrm{cm}^{-3}\right)$; D-konvektif düfüzyon parametresi, $\left(\mathrm{m}^{2}\right.$ gün$\left.^{-1}\right)$; v-toprak suyu akışının ortalama hızı $\left(\mathrm{m}\right.$ gün $\left.{ }^{-1}\right) ; \theta$ - yıkanması gereken toprak derinliğinde porozite (\%); $\gamma=\gamma_{1}+\gamma_{2}$ - toprağın tuzluluk türüne, içerdiği tuzlara ve toprağın fizikokimyasal özelliklerine bağlı olan sabitler; k-lineer Freundlich adsorpsiyon izoterminin doğrusal eşitliğinin ampirik sabiti; $\mu$-toprak çözeltisinde birinci dereceli kinetik model biçiminde olabilecek ayrışma hızı sabiti $\left(\right.$ gün $\left.^{-1}\right)$.

(1) nolu denklemeler, sistemin bir tane çözümünün belirlenmesi başlangıç ve sınır koşullarının yapılması gerekmektedir. Tuzlu toprakların yıkanması sürecini en uygun ifade eden başlangıç ve sınır koşulları aşağıdaki gibi ifade olunmaktadır:

$$
\begin{array}{ll}
t=0: & C(x, t)=S_{0} \\
x=0: & D \frac{\partial C}{\partial x}=v\left[C(0, t)-S_{w}\right] \\
x=L: & D \frac{\partial C}{\partial x}=0
\end{array}
$$

Burada; $\mathrm{S}_{0}$-toprak profilinin $[0, \mathrm{~L}]$ katmanındaki çözünmüş tuzların konsantrasyonu, $\left(\mathrm{me} \mathrm{L}^{-1}\right) ; \mathrm{S}_{\mathrm{w}}$-yıkama suyunun konsantrasyonu (me L ${ }^{-1}$ ); L- yıkanması gereken toprak katmanı (m).

Çok sayıda yapılan laboratuvar ve tarla denemeleri sonuçları, konvektif difüzyon parametresi ve toprak gözeneklerindeki çözünmüş tuzların hareket hızı $v(t)$ arasındaki bağıntının aşağıdaki biçimde olduğu saptanmıştır (Collins, 1961; Bear, 1972; Verigin, 1979, 1986):

$\mathrm{D}=\mathrm{D}_{\mathrm{m}}+\lambda|\mathrm{v}(\mathrm{t})|$

Ayrıca, toprak tuzlarının yıkanması sırasında konvektif difüzyon parametresi (D) değerinin, moleküler difüzyon katsayısı $\left(D_{m}\right)$ değerine göre daha büyük olduğu belirlenmiştir (Aydarov, 1985).

Burada; $\lambda$-hidrokimyasal dispersiyon (yayllma) veya hidrodinamik dispersiyon parametresi olarak adlanır (m) ve genelde toprağın tekstürüne, içermiş olduğu tuzların (iyonların) tipine ve yıkama suyunun gözeneklerdeki 
hızına bağlı olarak değişmektedir. Yıkama zamanı $\mathrm{D}_{\mathrm{m}} \approx 0$ ve $v>0$ olduğundan, eşitlik (5) ifadesi daha basit bir şekilde ifade olunmaktadır.

$\mathrm{Bu}$ durumda konvektif difüzyon parametresi hidrodinamik dispersiyon parametresi olarak adlandırılmaktadır (Aydarov, 1985).
Araştırma, Aksaray Üniversitesi yerleşkesinde, $38^{\circ}$ 22' kuzey enlemleri, $34^{\circ} 01^{\prime}$ doğu boylamları arasında yer alan Aksaray-Merkez ilçede yürütülmüştür. Topraklarının ağır-killi bir yapı ve arazi genelinde bitki yetişmesine engel olacak düzeyde tuzluluk, sodyumluluk ve borluluk durumuna sahip olduğu tespit edilmiş ve tuzluluk haritası Şekil 1'de verilmiştir.

\section{Materyal ve Yöntem}

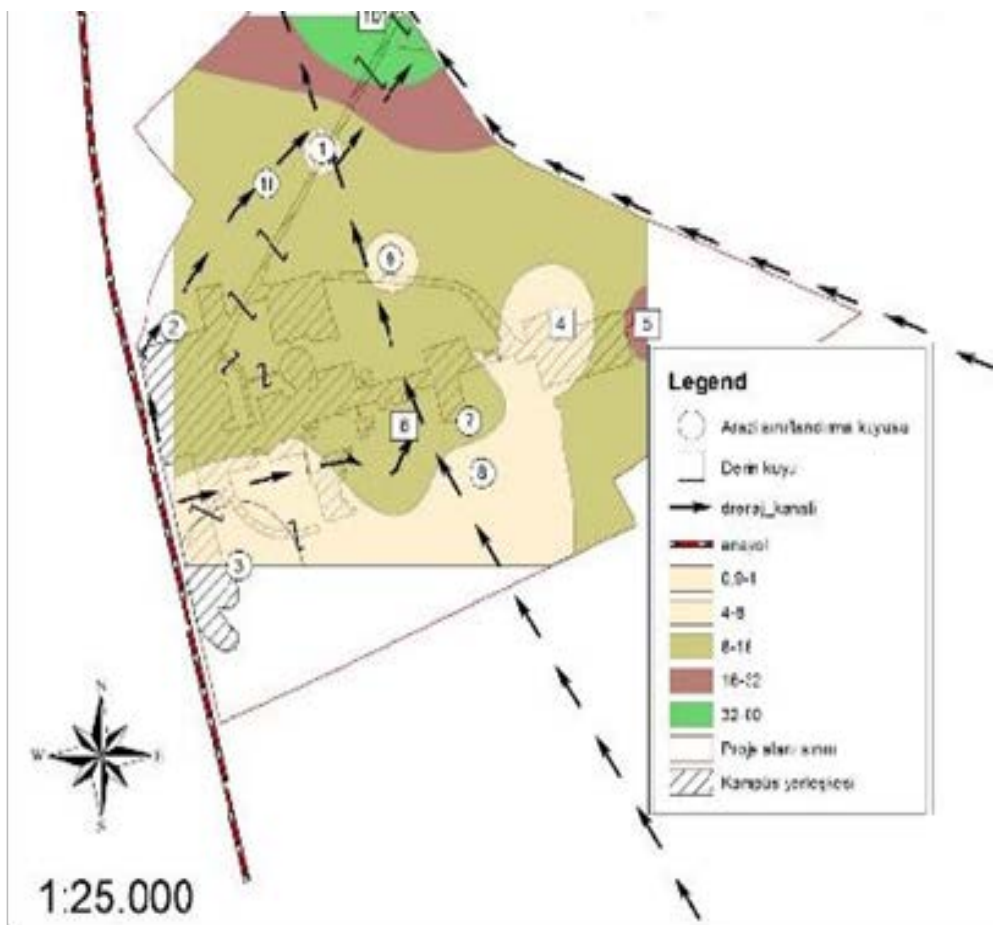

Şekil 1. Araştırma alanı toprağının tuzluluk hatları haritası (dS m$\left.{ }^{-1}\right)$ (DSİ, 2014).

Figure 1. Salinity lines map of the study area soil $\left(d S \mathrm{~m}^{-1}\right)(D S I$, 2014).

Kolonda yıkama öncesi deneme alanı içerisinden $0-10,10-20$ ve $20-30 \mathrm{~cm}$ derinliklerden toprak örnekleri alınmıştır.

Araziden alınan toprak örneklerinin fiziksel ve kimyasal özellikleri Çizelge 1'de, toprakların yıkama öncesi anyon ve katyon değerleri ise Çizelge 2'de verilmiștir. Cizelge 2'den görüldüğü gibi, alınan örneklerde suda çözünebilir iyonlardan klorür $\left(\mathrm{Cl}^{-}\right)$ve sülfat $\left(\mathrm{SO}_{4}{ }^{\circ}\right)$ toprakta tuz oluşumunu meydana getiren esas unsurlar olmaktadır.

Çizelge 1. Toprakların tuz yıkama katmanlarının fiziksel ve kimyasal özellikleri

Table 1. Physical and chemical properties of salt leaching layers of soils

\begin{tabular}{|c|c|c|c|c|c|c|c|}
\hline \multirow{2}{*}{$\begin{array}{l}\text { Toprak } \\
\text { derinliği } \\
\text { (cm) }\end{array}$} & \multirow{2}{*}{$\mathrm{pH}$} & \multirow{2}{*}{$\begin{array}{l}\text { Hacim } \\
\text { ağırllı̆g } \\
\left(\mathrm{g} \mathrm{cm}^{-3}\right)\end{array}$} & \multirow{2}{*}{$\begin{array}{l}\text { Parçacık } \\
\text { yoğunluğu } \\
\left(\mathrm{g} \mathrm{cm}^{-3}\right)\end{array}$} & \multirow{2}{*}{$\begin{array}{c}\text { Porozite } \\
\text { (\%) }\end{array}$} & \multicolumn{3}{|c|}{ Toprak bünyesi (\%) } \\
\hline & & & & & Kil & Silt & Kum \\
\hline $0-10$ & 9.21 & 13.2 & 1.23 & 2.59 & 69 & 22 & 9 \\
\hline $10-20$ & 8.76 & 13.1 & 1.23 & 2.55 & 83 & 12 & 5 \\
\hline $20-30$ & 8.13 & 17.1 & 1.25 & 2.60 & 55 & 32 & 13 \\
\hline Ortalama & 8.70 & 14.5 & 1.24 & 2.58 & 69 & 22 & 9 \\
\hline
\end{tabular}


Çizelge 2. Toprakların kolonda tuz yıkama öncesi anyon ve katyon değerleri

Table 2. Anion and cation values of soils before salt leaching in the column

\begin{tabular}{|c|c|c|c|c|c|c|c|c|c|c|}
\hline \multirow{3}{*}{$\begin{array}{l}\text { Toprak } \\
\text { derinliği } \\
\text { (cm) }\end{array}$} & \multicolumn{10}{|c|}{ Suda çözünebilir iyonlar } \\
\hline & \multicolumn{5}{|c|}{ Anyonlar $\left(\mathrm{me} \mathrm{L}^{-1}\right) \mathrm{S}_{0}$} & \multicolumn{5}{|c|}{ Katyonlar (me L ${ }^{-1}$ ) $\mathrm{S}_{0}$} \\
\hline & $\mathrm{CI}^{-}$ & $\mathrm{SO}_{4}=$ & $\mathrm{HCO}_{3}^{-}$ & $\mathrm{CO}_{3}=$ & $\sum$ & $\mathrm{Na}^{+}$ & $\mathrm{Ca}^{++}$ & $\mathrm{K}^{+}$ & $\mathrm{Mg}^{++}$ & $\sum$ \\
\hline $0-10$ & 94.31 & 26.70 & 6.50 & 2.30 & 129.81 & 101.74 & 0.60 & 28.62 & 0.15 & 131.10 \\
\hline $10-20$ & 89.60 & 32.45 & 4.00 & 0 & 126.05 & 99.50 & 0.92 & 22.19 & 0.84 & 123.45 \\
\hline $20-30$ & 129.32 & 34.15 & 3.47 & 0 & 166.94 & 132.17 & 0.54 & 28.82 & 5.63 & 167.16 \\
\hline Ortalama & 104.41 & 31.10 & 4.66 & 0.77 & 140.93 & 111.14 & 0.68 & 26.54 & 2.21 & 140.57 \\
\hline
\end{tabular}

Laboratuvarda tuz yıkaması için kullanılan kolon, 60 $\mathrm{cm}$ yüksekliğinde $20 \mathrm{~cm}$ genişliğinde kare şekilli, 2 mm'lik saçtan, sızdırmaz ve antipas boyası ile boyanmış metalden yapılmıştır. Ayrıca kolondan gerekli ölçümlerin yapılması için alınacak süzük örneği için vakum pompası kullanılmıştır. Vakum pompas1 plastik hortumlarla kolondaki katmanlara bağlanmıştır. Yıkama kolonu şeması Şekil 2'de, kolon yıkama suyu özellikleri ise Çizelge 3’te verilmiştir.

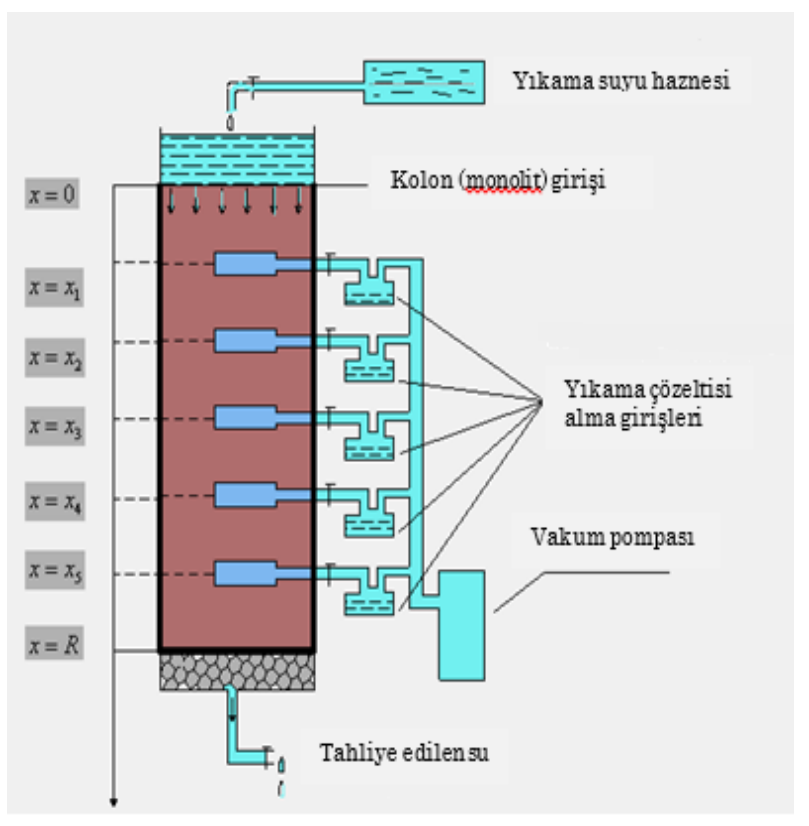

Şekil 2. Laboratuvar ortamında tuzlu toprak yıkama kolonu şeması

Figure 2. Saline soil leching column scheme in the laboratory

Çizelge 3. Yıkama suyu içeriği

Table 3. $\quad$ Leaching water content

\begin{tabular}{ccccccccccc}
\hline \multicolumn{10}{c}{ Suda çözünebilir iyonlar } \\
\hline \multicolumn{10}{c}{ Anyonlar $\left(\mathrm{me} \mathrm{L}^{-1}\right)$} & \multicolumn{1}{c}{ Katyonlar $\left(\mathrm{me} \mathrm{L}^{-1}\right)$} \\
\hline $\mathrm{CI}^{-}$ & $\mathrm{SO}_{4}{ }_{4}$ & $\mathrm{HCO}_{3}^{-}$ & $\mathrm{CO}^{-}{ }_{3}$ & $\sum_{\mathrm{A}}$ & $\mathrm{Na}^{+}$ & $\mathrm{K}^{+}$ & $\mathrm{Ca}^{++}$ & $\mathrm{Mg}^{++}$ & $\sum_{\mathrm{K}}$ & $\sum_{\mathrm{A}+\mathrm{K}}$ \\
4.32 & 2.54 & 0.74 & 0.00 & 7.60 & 1.25 & 0.41 & 4.48 & 1.58 & 7.72 & 15.32 \\
\hline
\end{tabular}

Tuz yıkama kolonuna araziden $30 \mathrm{~cm}$ derinlikten alınan bozulmamış toprak örneği konulmuştur. Laboratuvarda kolon yıkamaya geçmeden önce topraktaki çözünebilir tuzların toprak profili içeresinde çözünmeye başlaması, üniform bir şekilde dağılması ve yıkama suyunun verilmesiyle birlikte bütün toprak katmanında daha iyi yıkanma sağlanması amaciyla toprağa doygunluk suyu verilmiştir. Doygunluk suyu miktarı; toprağın hacmi $\left(\mathrm{m}^{3}\right)$ ve porozite'nin (\%) çarpımı ile hesaplanmıştır. 
Hesaplanan doygunluk suyu miktarı kolona üstten yavaş yavaş verilerek suyun infiltre olması sağlanmıştır. Doygunluk suyunun alttaki süzük alma yerinden damlaların görülmesiyle birlikte yıkama suyu kolona üstten eşit miktarda olacak şekilde verilmeye başlanmıştır. Profil katmanlarından alınan süzük örneklerinden, toprakta tuz oluşumun da rol oynayan $\mathrm{CI}^{-}$ve $\mathrm{SO}_{4}=$ iyonlarının IC okuması yapılmıştır.

\subsection{Tuz taşınım modeli parametresinin belirlenmesi}

Toprak gözeneklerinde çözülmüş tuzların yıkama suyu ile sslahının incelenmesi için, (1) kısmi türevli diferansiyel denkleminin analitik veya sayısal yöntemlerle çözümünün bulunması gerekir. Bunun için denklemin başlangıç ve sınır koşullarının belirlenmesi gerekmektedir. Toprakların yıkama sürecinde, kararsız rejim ortamında tuz taşınım sürecini tanımlayan, konvektif-difüzyon denkleminin ortalamalı - integral çözümü aşağıda gibi ifade olunmaktadır (Verigin ve ark.,1986):

$\frac{S_{\tau}-S_{w}}{S_{0}-S_{w}}=\varphi_{2}(\tau, \eta)$

$=\sum_{\mathrm{n}=1}^{\infty}(-1)^{\mathrm{n}+1} \times\left[\frac{\sin ^{2}\left(2 \mathrm{~h}_{\mathrm{n}}\right)}{2\left(\mathrm{~h}_{\mathrm{n}}^{2}+\eta^{2}+\eta\right)}\right]$

$\exp \left[2 \eta-\left(h_{n}^{2}+\eta^{2}\right) F o\right]$

Burada;

$\tau=\frac{\mathrm{N}_{\mathrm{ys}}}{\theta . \mathrm{L}}, \quad \eta=\frac{\mathrm{L}}{4 \lambda}, \quad \mathrm{r}=\sqrt{\frac{\eta}{\tau}}$,

Fo $=\frac{\tau}{\eta}$

$$
\begin{aligned}
& S(L, t)=L^{-1} \int_{0}^{L} C(x, t) d x, \\
& N_{y s}=\frac{N}{Q}, \quad v=\frac{N_{y s}}{\theta . t}, \quad \Xi=\frac{S_{\tau}-S_{w}}{S_{0}-S_{w}}
\end{aligned}
$$

$\mathrm{S}_{0}, \quad \mathrm{~S}_{\tau}$-yıkamadan önce ve sonra toprak gözeneklerindeki çözünmüş tuzların ortalama konsantrasyonu (me $\mathrm{L}^{-1}$ ), $\mathrm{S}_{\mathrm{w}}$-yıkama suyunun konsantrasyonu (me $\mathrm{L}^{-1}$ ), Q-yıkama kolonuna verilen su yüzey alanı $\left(\mathrm{m}^{2}\right)$, L-kolon yıkama yüksekliği $(\mathrm{m})$, $\theta$-porozite (gözeneklik) (\%), t-yıkama süresi (gün), Nyıkama için verilen $\mathrm{su}\left(\mathrm{m}^{3}\right), \mathrm{N}_{\mathrm{ys}}$-yıkama suyu normu (m) (Mikayilov, 2007).

$\varphi_{2}(\eta, \tau)$ fonksiyonlarının $\eta$ ve $\tau$ parametrelerinin tipik değerleri önceden hesaplanmıştır (Mikailov ve ark., 1985). $\mathrm{Bu}$ değerleri kullanılarak toprak gözeneklerinde tuz taşınımı miktarını tahmin etmekle birlikte, ayrica hidrokimyasal parametrenin de değerinin hesaplanması mümkündür.

Yıkama zamanı (5) ifadesi aşağıdaki biçimde ifade olunmaktadir:

Aşağıdaki eşitlik:

$\mathrm{D}=\lambda \cdot \mathrm{v}$

Burada; $D$-konvektif difüzyon parametresi [ $\mathrm{m}^{2}$ gün ${ }^{-1}$ ], $\lambda$ - dispersiyon (yayilma) parametresi (m), $\quad v-$ gözeneklerdeki su hızı $\left[\mathrm{m}\right.$ gün $\left.^{-1}\right]$. $\eta$ ve $\tau$ parametrelerine bağlı olarak hesaplanan $\lambda$ değerine göre D değeri hesaplanır. Hidrokimyasal parametrelerin geçerliliğinin belirlenmesi için yapılan sayısal işlemler Fortran VI paket programında yapılmıştır.

\section{Bulgular ve Tartışma}

Kolonda toprak y1kama sonucu tuz $\mathrm{CI}^{-}$ve $\mathrm{SO}_{4}{ }^{=}$ iyonlarının değerleri Çizelge 4 ve 5 'te verilmiştir.

Çizelge 4. Kolon tuz yıkama değerleri

Table 4. Colon salt leaching values

\begin{tabular}{cccccccc}
\hline \multirow{2}{*}{ Kolon } & $\mathrm{Q}\left(\mathrm{m}^{2}\right)$ & $\mathrm{L}(\mathrm{m})$ & $\theta(\%)$ & $\mathrm{t}($ gün$)$ & $\mathrm{N}\left(\mathrm{m}^{3}\right)$ & $\mathrm{N}_{\mathrm{ys}}(\mathrm{m})$ & $\mathrm{v}\left(10^{-2} \mathrm{~m}_{\text {gün}}{ }^{-1}\right)$ \\
\cline { 2 - 7 } & 0.04 & 0.30 & 0.5233 & 1.2083 & 0.0123 & 0.3075 & 4.6830 \\
\hline
\end{tabular}

Çizelge 5. Kolon tuz yıkama sonucu kolay çözünebilir anyonların değer girdileri

\begin{tabular}{|c|c|c|c|c|c|c|}
\hline \multirow{4}{*}{ Kolon } & & $\mathrm{S}_{\mathrm{w}}$ & $\mathrm{S}_{0}$ & $\mathrm{~S}_{\mathrm{t}}$ & $\tau$ & $\Xi$ \\
\hline & Anyonlar & & $\mathrm{me} \mathrm{l}^{-1}$ & & $\frac{\mathrm{N}_{\mathrm{ys}}}{\theta . \mathrm{L}}$ & $\frac{S_{\tau}-S_{w}}{S_{0}-S_{w}}$ \\
\hline & $\mathrm{Cl}^{-}$ & 4.3210 & 104.4107 & 9.6557 & 1.9587 & 0.0533 \\
\hline & $\mathrm{SO}_{4}=$ & 2.5430 & 31.0983 & 4.1143 & 1.9587 & 0.0550 \\
\hline
\end{tabular}

Table 5. Value inputs of easily soluble anions as a result of column salt leaching 
$\mathrm{CI}^{-}$ve $\mathrm{SO}_{4}{ }^{=}$iyonları için elde edilen $\lambda$ ve $D$ parametreleri hesaplanarak Çizelge 6'da verilmiştir. Elde edilen sonuçlara göre; hidrokimyasal dispersiyon parametresi $(\lambda)$, $\mathrm{Cl}^{-}$iyonu için $9.26 \cdot 10^{-2} \mathrm{~m} ; \mathrm{SO}_{4}{ }^{=}$iyonu için ise $9.60 \cdot 10^{-2} \mathrm{~m}$ olarak hesaplanmıştır.

Çizelge 6. Kolon yıkamada $\lambda$ ve $D$ değerleri

Table 6. $\quad \lambda$ and $D$ values in column leaching

\begin{tabular}{lc|c}
\hline & Anyonlar & Parametre değerleri \\
\hline \multirow{2}{*}{ Hidrodinamik dispersiyon parametresi $(\lambda),\left(10^{-2} \cdot \mathrm{m}\right)$} & $\mathrm{CI}^{-1}$ & 9.260 \\
\hline \multirow{2}{*}{ Konvektif difüzyon parametresi (D), $\left(10^{-3} \mathrm{~m}^{2}\right.$ gün$\left.^{-1}\right)$} & $\mathrm{SO}_{4}{ }^{=}$ & 9.600 \\
\hline
\end{tabular}

Kolon yıkamada hesaplanmış parametre değerleri Çizelge 7'de, okuma sayısı değerleri ise Çizelge 8'de verilmişsir.

Çizelge 7. Kolon yıkamada hesaplanmış $\lambda$ ve D parametre değerleri Table $7 . \quad \quad$ Calculated $\lambda$ and D parameter values in column leaching

\begin{tabular}{|c|c|c|c|c|c|c|c|}
\hline & & \multirow[b]{2}{*}{ 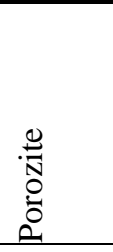 } & \multirow{2}{*}{ 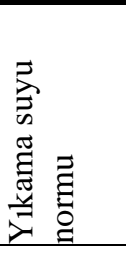 } & \multirow{2}{*}{ 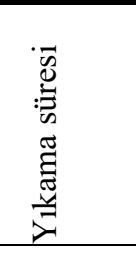 } & \multirow{2}{*}{ 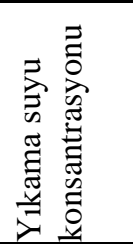 } & \multicolumn{2}{|c|}{$\begin{array}{c}\text { Toprağın 0-30 cm katmanında } \\
\text { mevcut ortalama Anyon } \\
\text { konsantrasyonu } \\
\end{array}$} \\
\hline & & & & & & $\begin{array}{l}\text { Yikamadan } \\
\text { önceki }\end{array}$ & $\begin{array}{l}\text { Yikamadan } \\
\text { sonraki }\end{array}$ \\
\hline & & $\theta$ & $\mathrm{N}_{\mathrm{ys}}$ & $\mathrm{T}$ & $S_{w}$ & $\mathrm{~S}_{0}$ & $\mathrm{~S}_{\mathrm{t}}$ \\
\hline & Anyonlar & $\%$ & $\mathrm{~m}$ & gün & \multicolumn{3}{|c|}{ me $\mathrm{L}^{-1}$} \\
\hline \multirow{2}{*}{ Kolon } & $\mathrm{Cl}^{-}$ & 0.5233 & 0.3075 & 1.20833 & 4.3210 & 104.4107 & 9.6557 \\
\hline & $\mathrm{SO}_{4}=$ & 0.5233 & 0.3075 & 1.20833 & 2.5430 & 31.0983 & 4.1143 \\
\hline
\end{tabular}

Çizelge $7 . \quad$ Devamı

Table $7 . \quad$ Continue
Konvektif difüzyon parametresi $(D)$ değerleri ise $\mathrm{Cl}^{-}$ iyonu için $4.51 \cdot 10^{-3} \mathrm{~m}^{2}$ gün$^{-1}$; $\mathrm{SO}_{4}{ }^{=}$iyonu için ise $4.67 \cdot 10^{-3} \mathrm{~m}^{2}$ gün ${ }^{-1}$ olarak belirlenmiştir.

\begin{tabular}{|c|c|c|c|c|}
\hline & 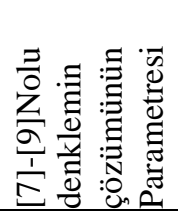 & 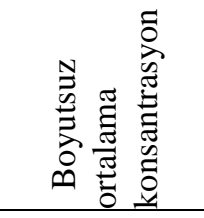 & 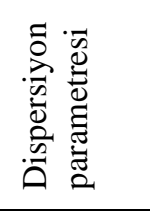 & 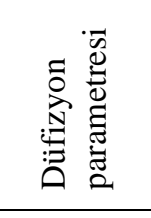 \\
\hline & $\tau=\frac{\mathrm{N}_{\mathrm{ys}}}{\theta . \mathrm{L}}$ & $\Xi=\frac{S_{\tau}-S_{w}}{S_{0}-S_{w}}$ & $10^{-2} \cdot \lambda$ & $10^{-3} \cdot \mathrm{D}$ \\
\hline Anyonlar & & $\mathrm{m}$ & $\mathrm{m}^{2} \cdot$ gün $^{-1}$ & $\mathrm{~m}^{2} \cdot$ gün$^{-1}$ \\
\hline $\mathrm{Cl}^{-}$ & 1.9587 & 0.0533 & 9.2600 & 4.5050 \\
\hline $\mathrm{SO}_{4}=$ & 1.9587 & 0.0550 & 9.6000 & 4.6720 \\
\hline
\end{tabular}


Çizelge 8. Okuma sayısı değerleri

Table $8 . \quad$ Readings values

\begin{tabular}{ccccccccc}
\hline № & $\theta$ & $\mathrm{N}_{\mathrm{ys}}$ & $\mathrm{t}$ & $\mathrm{L}$ & $\mathrm{v}$ & $\tau$ & $\eta$ & $\Theta \operatorname{Pr}$ \\
\hline 8099 & 0.523 & 0.307 & 1.21 & 0.30 & 0.048 & 1.959 & 0.809 & 0.053 \\
7809 & 0.523 & 0.307 & 1.21 & 0.30 & 0.048 & 1.959 & 0.780 & 0.055 \\
\hline
\end{tabular}

Çizelge 8. Devamı

Table $8 . \quad$ Continue

\begin{tabular}{ccccccc}
\hline № & Ө Ek & $\mathrm{Z} 2$ & $\lambda$ & $\mathrm{D}$ & $\mathrm{S}_{0}$ & $\mathrm{~S}_{\mathrm{t}}$ \\
\hline 8099 & 0.053 & 0.0001 & 0.092 & 0.0045 & 104.41 & 9.655 \\
7809 & 0.055 & 0.000095 & 0.096 & 0.0046 & 31.09 & 4.114 \\
\hline
\end{tabular}

\section{Sonuç}

Tuz taşınım probleminin çözümünün pratikte kullanılabilirliği ve güvenirliği önemli ölçüde modelin parametrelerinin hassas bir şekilde belirlenmesine bağlıdır. Tuz taşınım modelinin hidrokimyasal parametrelerinin tespit yöntemleri çoğu zaman "ters problemin” (modelin parametrelerinin belirlenmesi) çözümü esasında gerçekleştirilir. Elde edilen klor ve sülfat değerlerin birbirine yakın çıkması arazi şartlarının yıkama da önemli bir etken olacağ 1 öngörülmektedir.

Laboratuvar koşullarında kolon için hesaplanmış $\lambda, D$ ve $v$ parametreleri optimize edilerek, toprak-su-tuz rejiminin tahmininin yapilmasina ve bu tahminlerin büyük ölçekli tuzlu arazilerin yıkanmasında ve ıslahında kullanılabilir. Bu da su kaynaklarının daha verimli kullanılmasına ve sslah maliyetiyle birlikte zaman tasarrufuna da önemli katkı sağlayacaktır. Ayrıca, hidrokimyasal parametrelerin belirlenmesi, yıkanan arazilerin su-tuz dengesinin düzenlenmesinde de gerekli olmaktadır.

\section{Kaynaklar}

Aydarov, I.P., 1985. Regulation of water salt and nutrient regime of irrigated soils. Moscow, Press Agropromizdat, 304 p. ( in Russian).

Aydarov, I.P., Korol'kov A.I., Khachatur'yan V.K., 1988. Calculation of water-salt regime of soils. Pochvovedenie, 5: 62-69.

Bear, J., 1972. Dynamics of fluid in porous media. Elsevier Science, New York, 764 p.
Collins, R.E., 1961. Flow of fluids through porous materials. New York, Reinhold Publishing Corp, $270 \mathrm{p}$.

DSİ Genel Müdürlüğü, 4. Bölge Müdürlüğü, 2014. Aksaray Üniversitesi Kampüs Alanı Planlama Arazi Sinıflandırma ve Drenaj Raporu. Konya, Türkiye, 1601, 14s.

Dursun, S.A., 2017. Tuzlu-sodyumlu-borlu toprakların sslahı ve matematiksel modellenmesi. Doktora Tezi. Selçuk Üniversitesi Fen Bilimleri Enstitüsü, 49-55s, Konya.

Ekberli, İ., Gülser, C., Bayraklı, F., 2001. Sulanan toprakta hidrokimyasal dispersiyon parametresinin tayini. Ondokuz Mayıs Üniversitesi Ziraat Fakültesi Dergisi, 16 (1): 21-26.

FAO, 2008. htpp://www.fao.org/ ag/agl/agll/spush, Land and plant nutrition management service, (erişim tarihi: 2008).

Mikayilov, F.D., 1981. Method of lines in the solution of one-dimensional equation for salt diffusion in the soil in the absence of evaporation and water movement. Izv. Akad. Nauk Azerb. SSR, Ser. Biol. Nauk, 3: 117-120.

Mikayilov, F.D., Azizov, K.Z., 1985. Determination of the hydrochemical parameter of salt transfer during the leaching of water-saturated saline soils. Pochvovedenie, 5: 84-90.

Mikayilov, F.D., 2007. Determination of salt-transport model parameters for leaching of saturated superficially salted soils. Eurasian Soil Science, 40 (5): 544-554.

Pachepsky, Y.A., 1990. Mathematical models of physico-chemical processes in soils. Nauka, Moscow, Russian.

Shein, E.V., Arkhangel'skaya, T.A., Goncharov, V.M., et al., 2001. Field and laboratory methods of studying the physical properties and regimes of soils. Mosk. Gos. Univ., Moscow, (in Russian). 
Shein, E.V., 2005. Course of Soil Physics. Mosk. Gos. Univ., Moscow, Russian.

Sönmez, B., 2011. Çorak toprakların ıslahı ve yönetimi. Bilim ve Aklın Aydınlığında Eğitim, 134: 52-56.

Vaksman, E.G., Mironenko, E.V. and Pachepsky, Y.A., 1981. Method of determining salt-transfer parameter under leaching. Gidrotekhnika i Melioratsiya, 11: 83-84.

Verigin, N.N., 1953. Some Chemical Hydrodynamics Problems of Interest for Land Reclamation and Hydraulic Engineering. Izv. Akad. Nauk, SSSR, 7: 1369-1382.

Verigin, N.N., 1979. Toprakların ve Taban Sularının Tuz Rejiminin Tahminin Metotları. (Rusça), Moskova, 336p.

Verigin, N.N., Azizov, K.Z. and Mikayilov, F.D., 1986. Effect of boundary conditions in the simulation of salt transfer in soils under leaching. Pochvovedenie, 6: 67-73. 